\title{
SEISMIC LOAD TESTS ON TWO CONCRETE INTERIOR BEAM-COLUMN JOINTS REINFORCED BY PLAIN ROUND BARS DESIGNED TO PRE-1970s CODES
}

\author{
Aizhen Liu ${ }^{1}$ and R. Park ${ }^{2}$
}

\begin{abstract}
SUMMARY
Two identical reinforced concrete interior beam-column joint assemblies were tested under simulated seismic loading as part of an investigation of the behaviour of existing reinforced concrete structures designed to pre-1970s codes when subjected to severe earthquake forces. The test units were full-scale in size, and were replicas of part of the moment resisting frame of an existing building in Christchurch that was constructed in the 1950s. The longitudinal and transverse reinforcement were from plain round bars, the beams and columns had low quantities of transverse reinforcement and the joints had no shear reinforcement at all, as was typical of pre-1970s construction in New Zealand. One unit was tested with zero axial column load, and the other unit with a constant axial column load of $0.12 f_{c}^{\prime} \mathrm{A}_{\mathrm{g}}$, where $f_{c}^{\prime}=$ concrete cylinder compressive strength and $\mathrm{A}_{\mathrm{g}}=$ the gross column section area. The units displayed very low structural stiffness, flexural strength less than conventionally calculated, and significant degradation of stiffness and strength during testing. The low structural stiffness and flexural strength could be attributed to the slip of the plain round longitudinal bars through the joint. However, the utilisation of plain round bars although leading to bond slip was found to improve the joint shear strength and to result in reduced shear distortion of the joint. Buckling of longitudinal column bars was found to initiate failure, due to inadequate ties.
\end{abstract}

\section{INTRODUCTION}

Seismic design procedures have advanced significantly in New Zealand since about the 1970s $(1,2)$. These developments have brought about the realisation that many reinforced concrete structures constructed before the 1970 s may be deficient according to the seismic requirements of current codes, resulting in the development of several research programs in New Zealand and overseas; for example, References 3-12. Deficiencies often found in typical existing reinforced concrete moment-resisting frames are lack of a well identified mechanism of plastic deformation; inadequate quantities of transverse reinforcement for the shear resistance of beams, columns and beam-column joints; inadequate quantities of transverse reinforcement for the confinement of the compressed concrete and the prevention of premature buckling of longitudinal bars in members, especially in columns; and poor anchorage of reinforcement $(4,7-13)$.

Several realistic seismic assessment procedures based on capacity design philosophy have been developed based on determining the critical mechanism of inelastic behaviour ( 7 , $10,12)$. Once the information on the available strength and ductility of the critical mechanism of an existing reinforced

\footnotetext{
'Doctoral student, University of Canterbury,

New Zealand

${ }^{2}$ Professor of Civil Engineering, University of Canterbury, New Zealand (Life Member \& Ex-President)
}

concrete structure is determined, the seismic performance of the existing structure can be realistically assessed.

The aim of this research project is to obtain further information on the available stiffness, strength and ductility of existing reinforced concrete moment resisting frames by conducting tests on two interior beam- column joint assemblies reinforced by plain round longitudinal bars and having reinforcing details typical of the pre-1970s construction in New Zealand.

This research project forms part of a research program on Seismic Assessment and Retrofit of Existing Reinforced Concrete Structures, which has been conducted at the University of Canterbury for several years sponsored by the Earthquake Commission. A number of tests on other as-built reinforced concrete columns and beam-column joint subassemblies of buildings $(9,11)$ have been conducted under cyclic loading. The tests on the columns used plain round bars for longitudinal reinforcement (9). However, the previous tests on beam-column joints used deformed bars for longitudinal reinforcement (11). Plain round bar reinforcement was used in New Zealand until about the mid 1960s when deformed bar reinforcement became widely available. The bond strength of plain round bar 
reinforcement is low, compared with deformed bar reinforcement, particularly during cyclic loading. It is evident that the deterioration of the bond strength of longitudinal bars passing through beam-column joints may have a significant influence on the behaviour of reinforced concrete structures, especially on the stiffness and the flexural and shear strengths.

This paper reports the results from the tests on two one-way interior beam - column joint units which were reinforced by plain round reinforcement.

\section{DETAILS OF TEST UNITS}

Two identical one-way interior beam-column joint Units were constructed, each full-scale in size, containing plain round longitudinal and transverse reinforcement and with reinforcement details typical of the 1950s construction in New Zealand. The overall dimensions and reinforcing details of the two identical interior beam-column joint units are shown in Fig. 1. The beams were $500 \mathrm{~mm}$ in depth and 300 $\mathrm{mm}$ in width, and the columns were $300 \mathrm{~mm}$ in depth and $460 \mathrm{~mm}$ in width. The Units are identical to that part between the mid-span of the beams and the mid-height of the columns of an existing seven-storey reinforced concrete frame structure constructed in the 1950s in New Zealand, which has been described previously (11). The beams were unsymmetrically reinforced and contained four $24 \mathrm{~mm}$ diameter Grade 300 plain round bars in the top ( $p=1.36 \%$ ) and two $24 \mathrm{~mm}$ diameter Grade 300 plain round bars in the bottom $\left(p^{\prime}=0.68 \%\right)$. The beam transverse reinforcement was from $6 \mathrm{~mm}$ diameter Grade 300 plain round bars placed at $380 \mathrm{~mm}$ centres, and the first stirrup was $300 \mathrm{~mm}$ from the column face. The columns were symmetrically reinforced and contained three $24 \mathrm{~mm}$ diameter Grade 300 plain round bars on both sides $\left(p_{t}=1.97 \%\right)$. The column transverse reinforcement was from $6 \mathrm{~mm}$ diameter Grade 300 plain round bars placed at $230 \mathrm{~mm}$ centres, and the first tie was $100 \mathrm{~mm}$ from the beam face. The beam-column joint cores contained no transverse reinforcement; also, intermediate column bars at the mid-depth of the columns were absent.

The concrete for both Units was normal weight. The Units were cast in one stage positioned in the horizontal plane, for convenience. One implication of this casting position is that the thickness of fresh concrete cast below all reinforcement was less than $300 \mathrm{~mm}$. Therefore, the bond conditions for the top bars in the Units when positioned in the test frame would have been better than in normal construction. Table 1 lists details of concrete compressive cylinder strengths of Units 1 and 2 at the time of testing and the axial load ratios applied to the columns during testing. For both units, all R24 plain round longitudinal reinforcing bars were taken from the same steel batch. Similarly, all R6 transverse reinforcement was taken from the same steel batch. Table 2 lists details of the reinforcement used for Units 1 and 2.

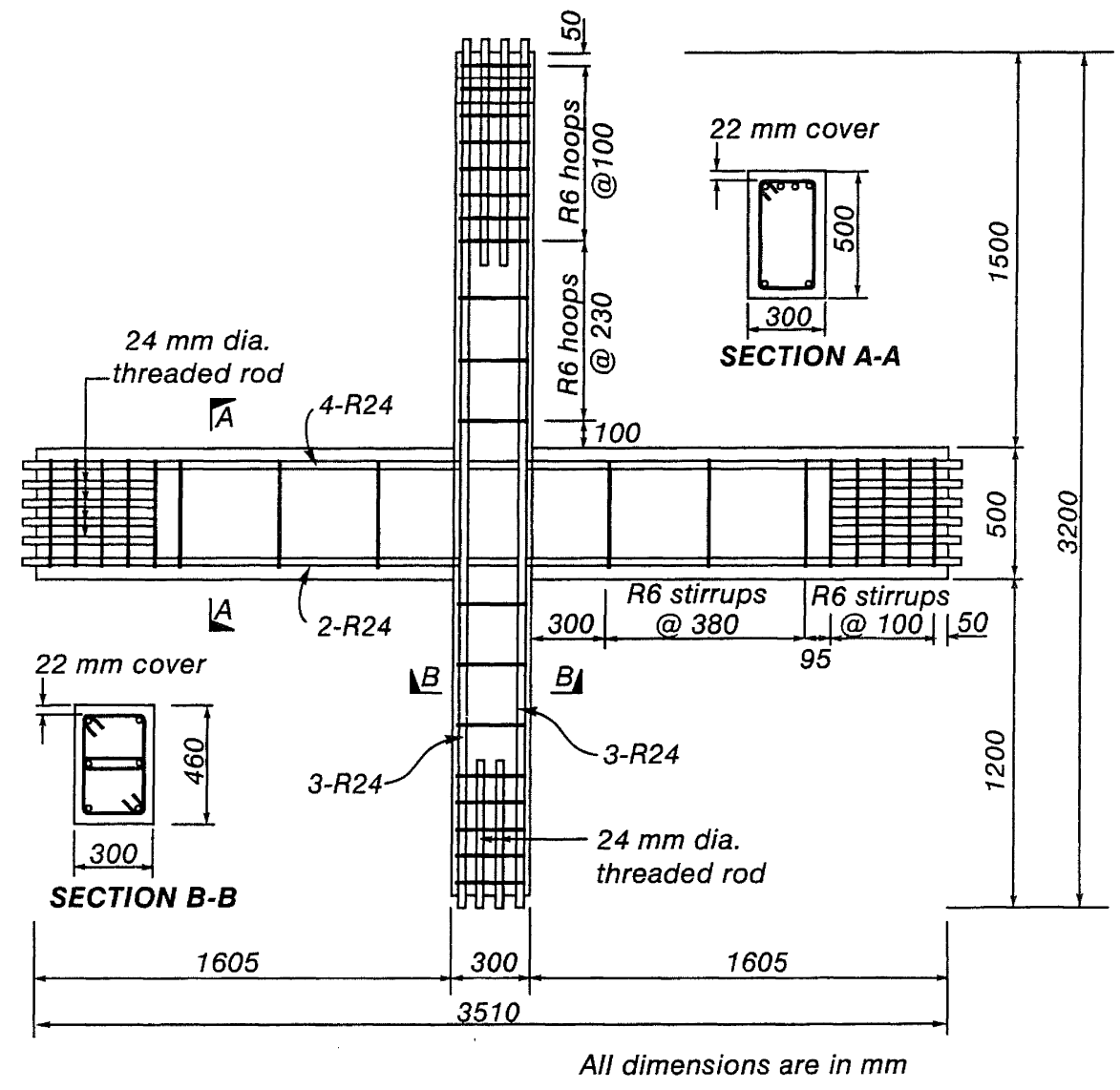

Figure 1: Reinforcement Details of the Two Interior Beam-Column Joint Specimens 
TABLE 1: Compressive Strengths of Concrete at the Time of Testing of Units

\begin{tabular}{|c|c|c|}
\hline Unit & $f_{c}^{\prime}(\mathbf{M P a})$ & $\mathbf{N}^{*} / \mathbf{A}_{\mathrm{g}} f_{c}^{\prime}$ \\
\hline Unit 1 & 43.8 & 0 \\
Unit 2 & 48.9 & 0.12 \\
\hline
\end{tabular}

TABLE 2: Details of Reinforcement in the Units

\begin{tabular}{|c|c|c|c|c|c|c|c|c|c|}
\hline \multirow{2}{*}{$\begin{array}{l}\text { Part of } \\
\text { Uritt }\end{array}$} & \multicolumn{6}{|c|}{ Longitudinal Reinforcement } & \multicolumn{3}{|c|}{ Transverse Reinforcement } \\
\hline & $\begin{array}{c}\mathrm{db}_{\mathrm{b}} \\
(\mathrm{mm})\end{array}$ & $\begin{array}{c}f_{y} \\
(\mathrm{MPa})\end{array}$ & $\begin{array}{c}\varepsilon_{y} \\
\times 10^{-6}\end{array}$ & $\begin{array}{c}\mathrm{p} \\
\%\end{array}$ & $\begin{array}{l}\text { p' } \\
\%\end{array}$ & $\begin{array}{l}p_{t} \\
\%\end{array}$ & $\begin{array}{c}\mathrm{d}_{\mathrm{b}} \\
(\mathrm{mm})\end{array}$ & $\begin{array}{c}f_{y t} \\
(\mathrm{MPa})\end{array}$ & $\begin{array}{c}\mathrm{s} \\
(\mathrm{mm})\end{array}$ \\
\hline Beam & 24 & 321 & 1560 & 1.36 & 0.68 & & 6 & 318 & 380 \\
\hline Column & 24 & 321 & 1560 & & & 1.97 & 6 & 318 & 230 \\
\hline
\end{tabular}

\section{THEORETICAL CONSIDERATIONS}

The flexural strengths of the beams and columns were calculated for both units using the measured material strengths, and assuming an extreme fibre concrete compressive strain of 0.003 , a rectangular compressive stress block as recommended by NZS3101: 1995(2) and a strength reduction factor $\phi$ of unity. The calculation was made on the basis of the assumption of perfect bond between steel and concrete. The curvatures at first yield and at ultimate for the beans and the columns were also calculated for both units assuming no bond slip of longitudinal bars using standard theory (1). The ultimate curvature was calculated assuming that the ultimate compressive strain of the concrete was 0.004 , which is a lower limit for the strain just before crushing and spalling of the compressed concrete. The theoretical flexural strengths, yield curvatures, ultimate curvatures and curvature ductility factors of the members are summarised in Table 3. From Table 3 it is evident that during simulated seismic load testing Unit 1 would develop plastic hinges in the columns and Unit 2 would develop plastic hinges in the bearns. The storey shear at the theoretical flexural strengths of the critical nembers of the units was 80 $\mathrm{kN}$ for Unit 1 and $128 \mathrm{kN}$ for Unit 2 .

The investigation of the effect of the amount of transverse reinforcement in the members and the joints is of particular interest. The imposed shear forces on the members and the joints during testing, which are associated with the above calculated theoretical flexural strengths of the units, are compared with the available shear strengths of the members and the joints, in Table 4. The available shear strengths of the plastic hinge regions were calculated using the methods of NZS 3101:1995(2) for structures designed for ductility, using the measured material strengths and assuming a strength reduction factor $\phi$ of unity. The shear strengths of the other regions were calculated using the non-seismic provisions of NZS 3101:1995. It is to be noted that NZS 3101 does not give a method for calculating the shear strength of existing beam-column joints. The amount of transverse reinforcement needed to restrain the longitudinal bars against premature buckling in plastic hinge regions according to NZS 3101:1995 (2) for structures designed for ductility are also compared with the actual quantities in Table 4. For the Units the column axial load ratios were low and hence the transverse reinforcement required in the columns to confine the concrete was not as critical as that required to prevent bar buckling.

From Table 4, it is apparent that, for both Units, both the spacing and the diameter of the beam and column transverse reinforcement in the plastic hinge regions met neither the requirements of NZS3101:1995 for shear strength nor the requirements for the prevention of longitudinal bar buckling for structures designed for ductility.

Also shown in Table 4 in brackets are the shear force capacities of the beams, columns and beam=column joints calculated using the methods recommended in Reference 12 . It is evident that the shear force capacities so calculated are greater than those calculated using NZS 3101:1995(2). For the Units the shear force capacities calculated using the methods of Reference 12 were adequate except for the beams of Unit 2 and the beam-column joint of Unit 1 . The methods of Reference 12 were derived from limited experimental evidence obtained from beam-column joint assemblies reinforced by deformed longitudinal reinforcement.

The development length of longitudinal reinforcing bars within interior beam-column joints is also of concern, especially when plain round longitudinal reinforcement is 
used. For the longitudinal beam bars, the ratio of column depth to beam bar diameter for both Units was $h_{c} / d_{b}=12.5$. According to NZS3101:1995(2), the ratio of column depth to beam bar diameter for ductile frames, when deformed longitudinal bars are used, should be not less than 16.5 for Unit 1 assuming that plastic hinges form in the columns and 19.4 for Unit 2 assuming that plastic hinges form the beams. The use of plain round longitudinal bars in the Units would require at least twice this needed development length, and on this approximate basis the ratio of column depth to beam bar diameter should not have been less than at least 33.0 for Unit 1 and 38.8 for Unit 2. Therefore, the available development length of the plain round beam bars was quite inadequate. For the longitudinal column bars, the ratio of beam depth to column bar diameter for both interior beam-column joint Units was 20.8. According to NZS3101:1995, for ductile frames the ratio of beam depth to column bar diameter, when deformed longitudinal bars are used, should not be less than 15.1 for Unit 1 assuming that plastic hinges form in the columns and 11.5 for Unit 2 assuming that plastic hinges form in the beams. As before, the use of plain round longitudinal bars would require at least twice this needed development length, and this means that the ratio of beam depth to column bar diameter should not have been less than at least 30.2 for Unit 1 and 23.0 for Unit 2. Again, the available development length of the plain round column bars was inadequate. Hence significant bond degradation, resulting in slip along the longitudinal bars, would be expected within the beam-column joint region of both Units.

\section{TEST PROCEDURE}

\subsection{Simulated Seismic Loading}

The method of loading Units 1 and 2 is shown in Fig. 2. The axial compressive load ratio $\mathrm{N}^{*} / f_{c}^{\prime} \mathrm{A}_{\mathrm{g}}$ applied to the columns was zero for Unit 1 and 0.12 for Unit 2 , where $\mathrm{N}^{*}=$ compressive axial load on column, $f_{c}^{\prime}=$ concrete compressive cylinder strength and $\mathrm{A}_{g}=$ gross area of the column. During the tests the column ends were held against horizontal translation while the beam ends were translated vertically, each by equal amounts, to simulate the loading and displacements applied during a severe earthquake. The ends of the beams and columns were free to rotate and to move axially. The first two loading cycles at the beam ends were load-controlled, including one cycle to $50 \%$ of the theoretical flexural strength of the unit and one cycle to $75 \%$ of the theoretical flexural strength of the unit. These two cycles in the elastic range were followed by a series of displacement-controlled inelastic cycles comprising two full cycles to each of displacement ductility factors of 1,2 and 3 . The "first yield" displacement was found by extrapolating the measured stiffness at $75 \%$ of the theoretical flexure strength linearly up to the theoretical flexural strength.

The imposed vertical displacements at the ends of the beams, $\Delta$, were converted to equivalent storey (horizontal) displacements at the ends of the columns for when the beam ends remained undeflected, using the geometry of the frame. The equivalent storey (horizontal) displacement $=\Delta \mathrm{x}$ $3,200 / 3,810=0.84 \Delta$. The equivalent storey drift as a percentage is then given by $(0.84 \Delta / 3,200) 100=\Delta / 38.1$.

It is to be noted that in situations when the first yield displacement as defined above is large the attained storey drift is a more useful measure of deformation capacity of the subassemblage than the displacement ductility factor, since in that case high displacement ductility factors are associated with unrealistically high drifts.

\subsection{Instrumentation}

The displacement components were monitored using linear potentiometers. Beam and column curvatures were measured using linear potentiometers attached to steel studs which passed through the concrete core. Of special importance was that for both Units 1 and 2 the beam and column rotations at the cracks at the faces of the joint core were measured using pairs of linear potentiometers located next to the joint core. These rotations are mainly associated with the deformations of the longitudinal reinforcement within the joint region and the ends of the adjacent members due to bond slip and will be referred to as the "fixed-end" rotations. The joint shear distortion was also measured by linear potentiometers which were diagonally attached to the horizontal steel bars which were embedded in the concrete core. In addition, the longitudinal reinforcement strains were measured using electrical resistance strain gauges as well as by linear potentiometers which were attached to the ends of steel studs which had been welded to the longitudinal reinforcement and projected laterally through holes in the cover concrete.

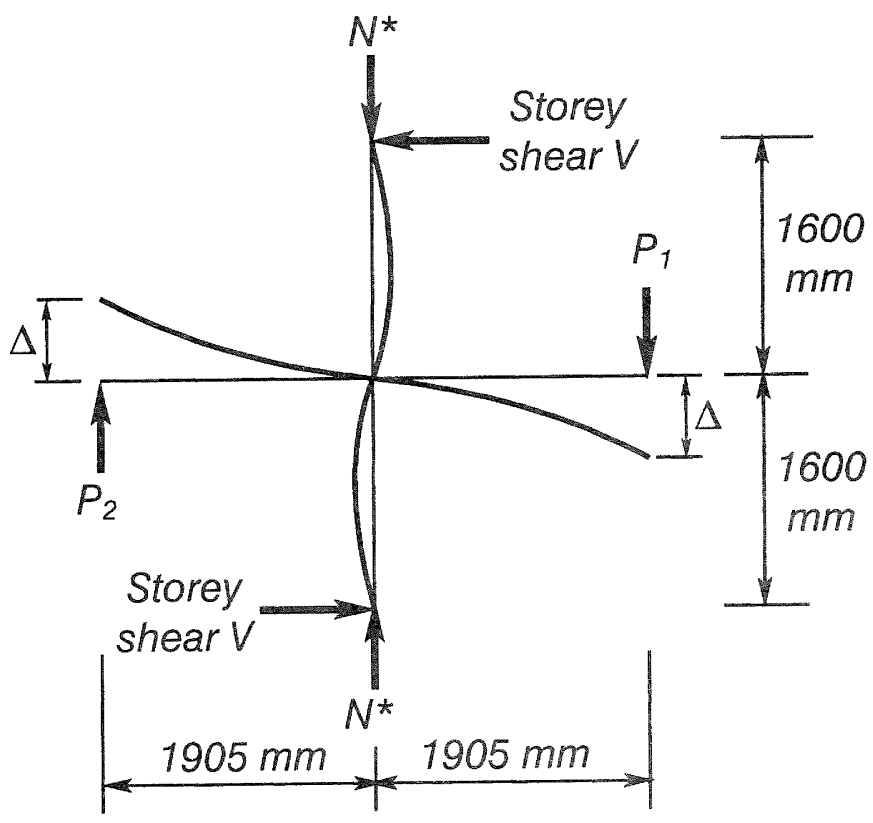

Figure 2: Method of loading the two interior beamcolumn joint units. 
TABLE 3: Theoretical Flexural Strengths and Curvature Properties of Members for Units 1 and 2

\begin{tabular}{|c|c|c|c|c|c|c|}
\hline & & $\begin{array}{l}\text { Flexural } \\
\text { Strengths of } \\
\text { Members } \\
(\mathbf{k N m})\end{array}$ & $\begin{array}{c}\text { Yield } \\
\text { Curvature } \\
\phi_{\mathbf{y}\left(\mathrm{mm}^{-1}\right)} \\
\left(\begin{array}{r}\left.\times 10^{-6}\right) \\
+\end{array}\right.\end{array}$ & $\begin{array}{c}\text { Ultimate } \\
\text { curvature } \\
\phi_{\mathbf{u}\left(\mathrm{mm}^{-1}\right)} \\
\begin{array}{r}\left(\mathrm{x} \mathrm{10} 0^{-5}\right) \\
+\end{array}\end{array}$ & $\begin{array}{c}\text { Available } \\
\text { curvature } \\
\text { factor } \\
\phi_{\mathbf{u}} / \phi_{\mathbf{y}} \\
+\end{array}$ & $\frac{\sum \mathbf{M}_{\text {column }}}{\sum \mathbf{M}_{\text {beam }}}$ \\
\hline \multirow{3}{*}{ Unit 1} & $\begin{array}{l}\text { beam positive } \\
\text { moment }\end{array}$ & 129 & 4.4 & 10.3 & 23 & \multirow{3}{*}{0.57} \\
\hline & $\begin{array}{l}\text { beam negative } \\
\text { moment }\end{array}$ & 250 & 5.0 & 8.0 & 16 & \\
\hline & $\begin{array}{l}\text { column } \\
\text { moment* }\end{array}$ & 108 & 8.6 & 10.6 & 12 & \\
\hline \multirow{4}{*}{ Unit 2} & $\begin{array}{l}\text { beam positive } \\
\text { moment }\end{array}$ & 129 & 4.4 & 10.8 & 25 & \multirow{4}{*}{1.05} \\
\hline & & & & & & \\
\hline & $\begin{array}{l}\text { beam negative } \\
\text { moment }\end{array}$ & 251 & 5.0 & 8.0 & 16 & \\
\hline & $\begin{array}{l}\text { column } \\
\text { moment** }\end{array}$ & 198 & 10.7 & 6.4 & 6.0 & \\
\hline
\end{tabular}

+ Calculated assuming no bond slip of longitudinal bars.

* with zero axial present

** with axial load present of $0.12 f_{c}^{\prime} \mathrm{A}_{\mathrm{g}}$

TABLE 4: Shear Forces Imposed and Shear Capacities of Beams, Columns and Joints and Lateral Restraint of Longitudinal Bars

\begin{tabular}{|c|c|c|c|c|c|c|c|c|}
\hline \multirow{3}{*}{$\begin{array}{l}\text { Parts of } \\
\text { Units }\end{array}$} & \multicolumn{4}{|c|}{ Shear } & \multicolumn{4}{|c|}{$\begin{array}{l}\text { Transverse Reinforcement for Lateral Restraint } \\
\text { of Longitudinal Bars in Plastic Hinge Zones }\end{array}$} \\
\hline & \multicolumn{2}{|c|}{ Unit 1} & \multicolumn{2}{|c|}{ Unit 2} & \multicolumn{2}{|c|}{ Required amount } & \multicolumn{2}{|c|}{ Actual amount } \\
\hline & $\begin{array}{l}\text { Maximum } \\
\text { Imposed } \\
\text { Shear } \\
\text { Force }(\mathrm{kN})\end{array}$ & $\begin{array}{c}\text { Shear } \\
\text { Force } \\
\text { Capacity } \\
(\mathbf{k N})\end{array}$ & $\begin{array}{c}\text { Maximum } \\
\text { Imposed } \\
\text { Shear } \\
\text { Force } \\
(\mathrm{kN})\end{array}$ & $\begin{array}{c}\text { Shear } \\
\text { Force } \\
\text { Capacity } \\
(\mathbf{k N})\end{array}$ & $\begin{array}{c}\text { Maximum } \\
\text { Spacing } \\
(\mathrm{mm})\end{array}$ & $\begin{array}{c}\text { Minimum } \\
\text { Area per } \\
\text { set } \\
\left(\mathrm{mm}^{2}\right)\end{array}$ & $\begin{array}{c}\text { Spacing } \\
(\mathrm{mm})\end{array}$ & $\begin{array}{c}\text { Area } \\
\text { per } \\
\text { set } \\
\left(\mathrm{mm}^{2}\right)\end{array}$ \\
\hline Beams & 67 & $146(204)$ & 143 & $22(70)$ & 115 & 91 & 380 & 57 \\
\hline Columns & 80 & $41(134)$ & 128 & $250(358)$ & 75 & 91 & 230 & 113 \\
\hline $\begin{array}{l}\text { Joint } \\
\text { (horizontal) }\end{array}$ & 483 & $-(268)$ & 744 & $-(783)$ & 240 & 95 & $\infty$ & 0 \\
\hline
\end{tabular}

Note: 1. Maximum imposed shear forces and shear force capacities are calculated assuming that the plastic hinges formed in the columns of Unit 1 and in the beams of Unit 2.

2. Maximum imposed shear forces are calculated assuming that the Units reached their flexural strengths at the plastic hinges. 
Notes to TABLE 4 continued:

3. Shear force capacities shown without brackets are those calculated using the methods of NZS 3101:1995(2) for ductile frames at the plastic hinges and for elastic behaviour elsewhere.

4. Shear force capacities shown with brackets are those calculated using the methods of Reference 12 assuming curvature ductility factors greater than 10 at the plastic hinges and elastic behaviour elsewhere. That is, the values of $\mathrm{k}$ used were:

Unit 1 : For beams $\mathrm{k}=0.2$, columns $\mathrm{k}=0.1$ and joint $\mathrm{k}=0.3$

Unit 2 : For beams $\mathrm{k}=0.05$, columns $\mathrm{k}=0.29$ and joint $\mathrm{k}=0.3$

\section{PERFORMANCE OF THE AS-BUILT INTERIOR BEAM- COLUMN JOINTS}

\subsection{Unit 1}

\subsubsection{Cracking and Damage}

The appearance of Unit 1 at the end of testing is shown in Fig. 3. The damage in general was observed to concentrate in the columns. The column displacement component contributed $70 \%$ and $90 \%$ of the total storey displacement at the beginning of the test and at the final testing stage, respectively. This observation was in accordance with the predicted weak column-strong beam failure mechanism expected. The damage to the columns tended to concentrate in horizontal flexural cracks in the columns at top and bottom of the joint panel. This occurred as a result of rapidly increasing column fixed-end rotations, which were associated with significant bond degradation and slip of the longitudinal column bars. Vertical cracks running through the joint core also developed along both layers of the longitudinal column bars, and this was associated with column bar buckling resulting from inadequate transverse restraint against bar buckling. Although some damage to the beams occurred by way of vertical flexural cracks in the beams adjacent to the joint panel, it was not so pronounced as that of the columns, indicating that bond degradation and slip were not so severe in the beams as in the columns. The later loading stages caused further progress of bond degradation and bar slip, especially in the columns. No diagonal tension cracks were observed in the columns or beams throughout the whole test. At the theoretical flexural strength of the columns the nominal shear stress in the columns was $0.10 \sqrt{f_{c}^{\prime}}$ and in the beams was $0.073 \sqrt{f_{c}^{\prime}}$. The actually attained nominal shear stresses were lower than those values and evidently were not high enough to cause diagonal tension cracking. Hence transverse reinforcement in Unit 1 was more needed for preventing bar buckling than for providing shear strength. Buckling of the longitudinal bars in the columns due to inadequate ties initiated the final failure of the unit. The beam-column joint region had developed only minor diagonal tension cracks at the end of the test.

\subsubsection{Load Versus Displacement Response}

Figure 4 shows the storey (horizontal) shear force versus storey (horizontal) displacement and drift hysteresis loops for Unit 1. Also shown is the ideal theoretical storey shear strength of the unit, $\mathrm{V}_{\mathrm{i}}$, calculated from the theoretical column flexural strengths using the New Zealand code approach (2) but using the measured material strengths and assuming a strength reduction factor of unity as previously described. Figs. 5 and 6 show the vertical deflections at the beam ends plotted against the corresponding beam vertical forces for Unit 1. These plots confirm the poor generally behaviour of the unit.

The first yield displacement obtained from the tests for Unit 1 determined using the method described in Section 4.1 was $57 \mathrm{~mm}$, which was equivalent to a storey drift of $1.8 \%$. This is nearly three times the first yield displacement of $20 \mathrm{~mm}$ predicted by conventional theory. This theoretically predicted first yield displacement did not include the effect of the fixed-end rotations due to bond slip in the joint and in the members. Also of interest is that the first yield displacement obtained from the tests for Unit 1 was larger than the value obtained in a previous test on an otherwise identical beamcolumn joint assembly reinforced by deformed bars in which the storey drift was $1.2 \%$ at the first yield displacement (11). This means that the type of structure tested would become extremely flexible when plain round bars are used for longitudinal reinforcement. On this basis the displacement ductility factor calculated using the measured first yield displacement becomes meaningless. Storey drift becomes a much better index of the displacement of the subassemblage.

Significant pinching of the loops is evident in Figs. 4, 5 and 6. The pinching started at the early loading stages and became more and more severe with the imposed displacement level. The softness of the test unit at the beginning of each loading run occurred at the stage before the commencement of the concrete contribution to the flexural compression. The softness was due to the major open flexural cracks adjacent to the joint core in the compression zones of the columns and the beams caused by tension in the previous loading run. These wide flexural cracks adjacent to the joint core were associated with the significant bond degradation and bar slip of the longitudinal reinforcement within the joint region and at the adjacent ends of the members. After the two faces of the major cracks closed together, shear and compression could be transferred along and across these cracks and the stiffness increased rapidly again. 


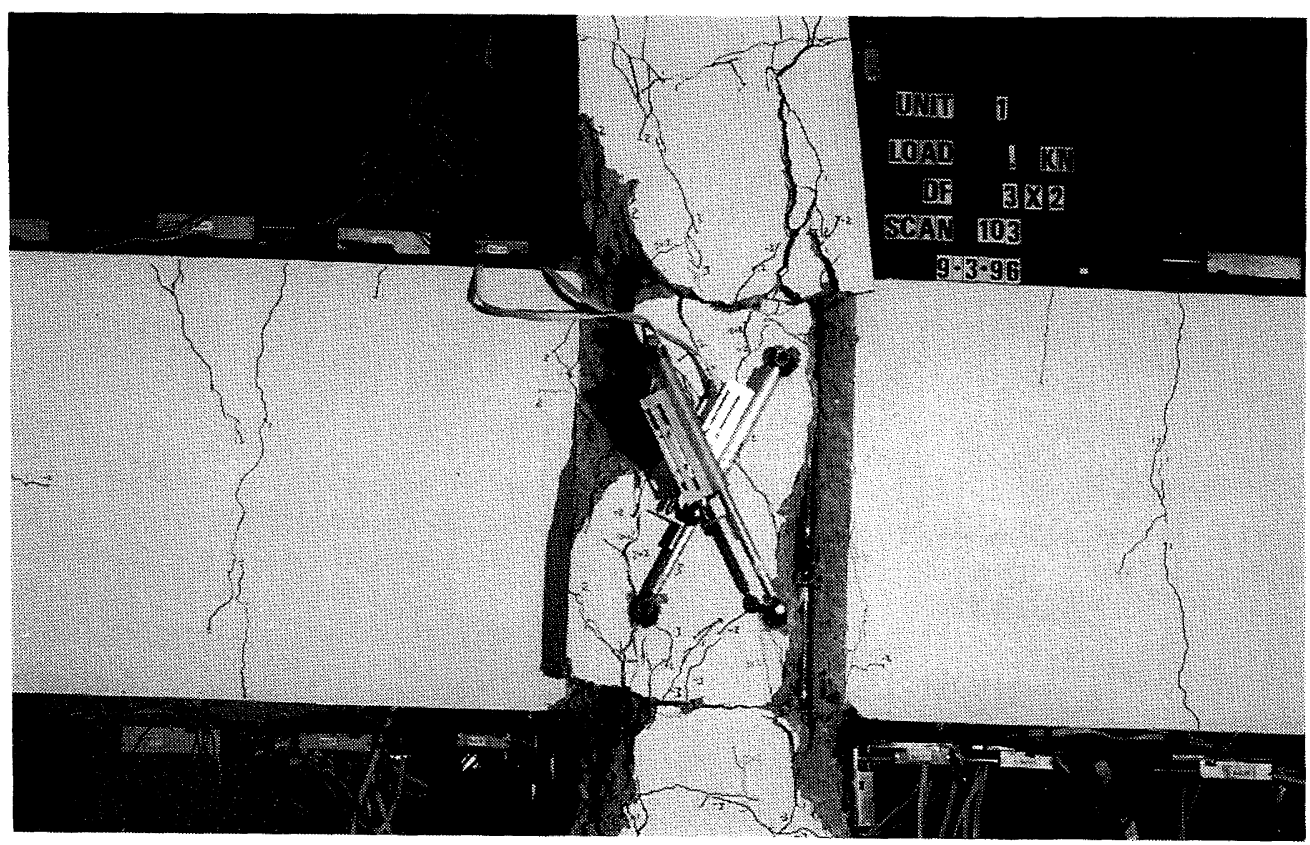

Figure 3: Final Appearance of Unit 1 with Column Failure

storeydrift (\%)

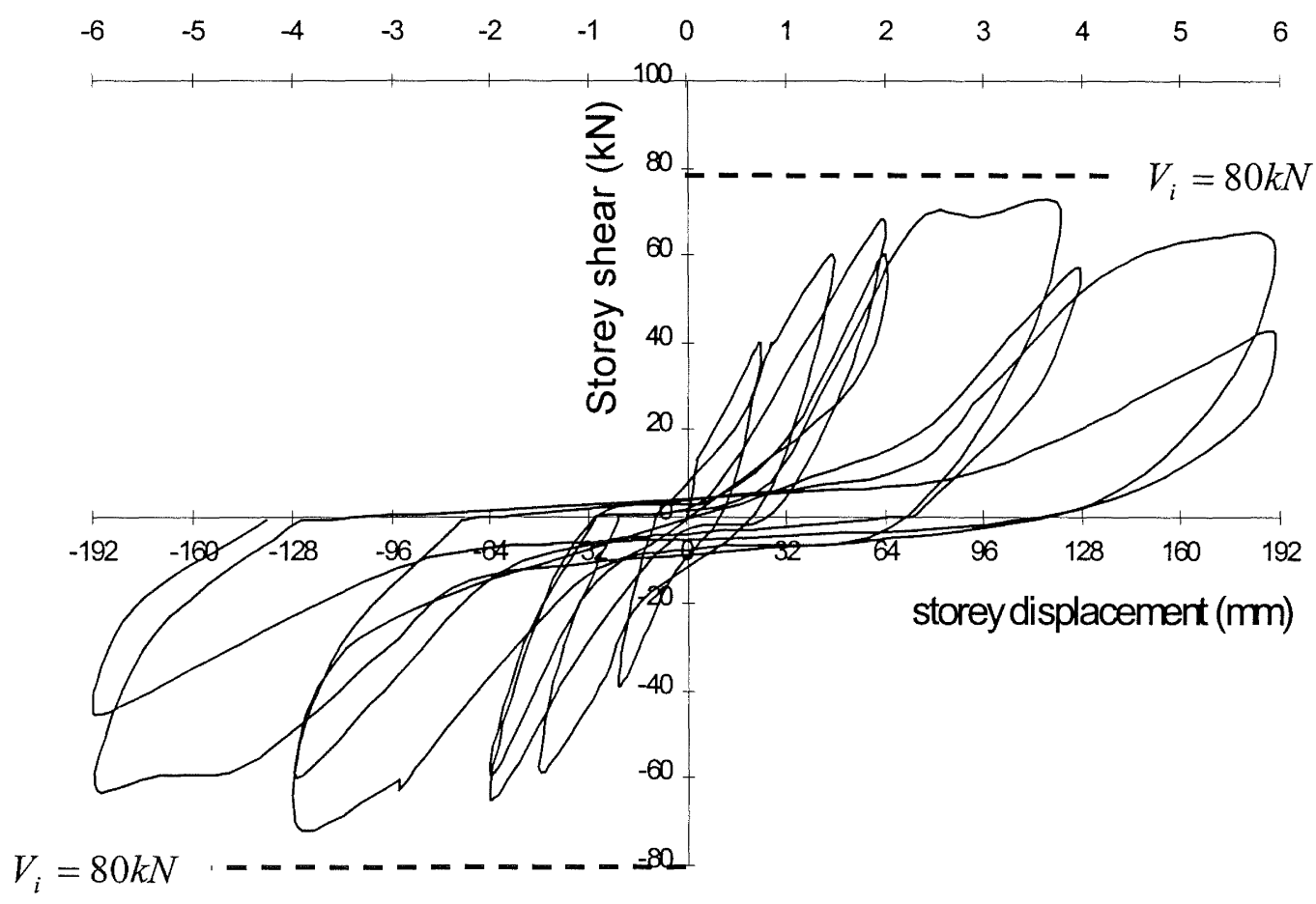

Figure 4: Hysteresis Loops for Storey Shear Versus Storey Displacement of Unit 1 


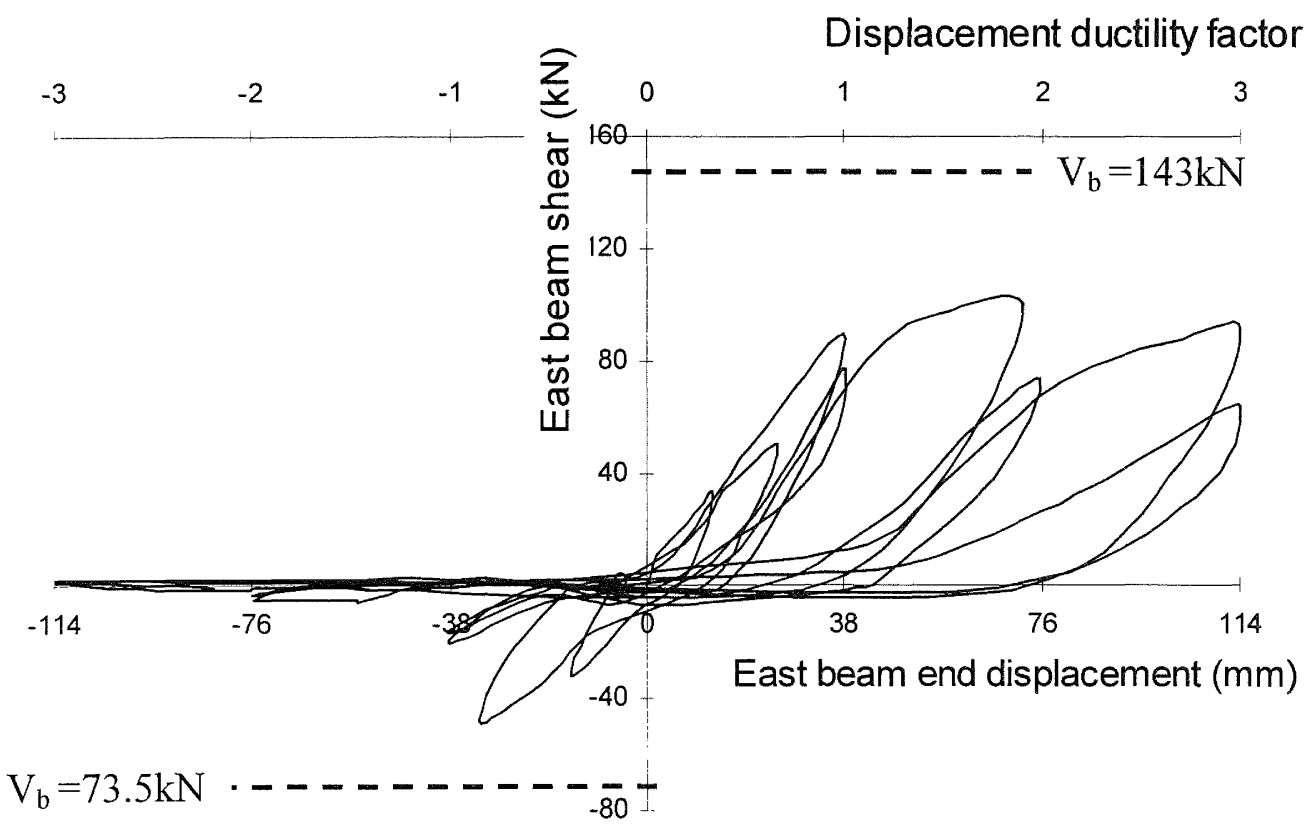

Figure 5: Hysteresis Loops for Beam Shear Versus Beam End Displacement of East Beam of Unit 1

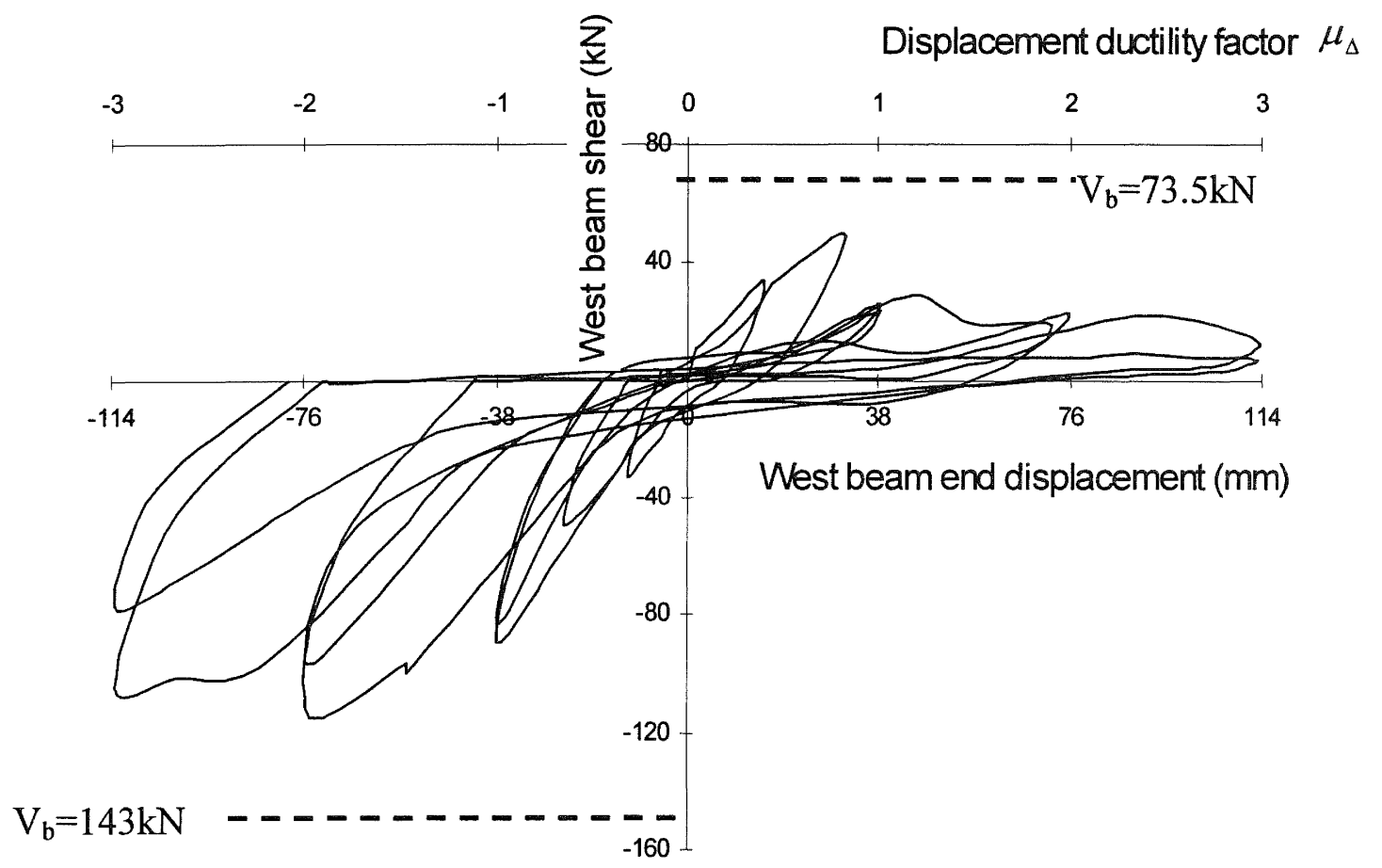

Figure 6: $\quad$ Hysteresis Loops for Beam Shear Versus Beam End Displacement of West Beam of Unit 1 
Figure 4 shows that unlike well-designed beam-column joint units where the theoretical strength or even the overstrength can be achieved, the maximum strength measured for Unit 1 , which was attained in the first loading run to a storey drift of almost $4 \%$, was about $10 \%$ less than the theoretical strength of the unit of $80 \mathrm{kN}$ in terms of the storey shear. The low measured maximum strength was due to severe bond degradation and slip of the longitudinal reinforcing bars, especially in the columns, which caused the plane section theory to overestimate the actual flexural strengths of the members at the plastic hinges.

Figure 4 also shows that Unit 1 demonstrated a significant reduction in strength with increase in the imposed displacements after the maximum strength was attained. In addition, the second loading cycle to the same displacement level resulted in a very significant strength degradation compared with the first cycle. This was due to the progressive bond slip and buckling of the longitudinal column bars under cyclic loading.

In summary, Unit 1 reached storey shears that were approximately $15 \%$ and $10 \%$ less than the theoretical storey shear strengths at storey drifts of approximately $2 \%$ and $4 \%$, respectively, accompanied by a great deal of softening with cyclic loading and pinching of the hysteresis loops.

\subsubsection{Measured Strains and Curvatures}

The longitudinal strains measured by electrical resistance strain gauges and linear potentiometers mounted on the main bars indicated that even during the initial elastic loading cycles severe bond degradation occurred. The measured longitudinal strains indicated that adjacent to the joint panel, the longitudinal "compression" bars actually were in tension. This was evidently due to significant bond degradation and bar slip through the joint core resulting in the conventional tension reinforcement in the beam on one side of the joint being anchored in the beam on the other side of the joint. Hence the plane section theory was significantly violated.

Also, the bond degradation caused smaller forces to be transmitted from reinforcing steel to the concrete by bond between the cracks, leading to the formation of fewer but wider cracks.

The strains on transverse reinforcement measured by electrical resistance strain gauges never reached the yield strains, and this finding agreed well with the observed test evidence.

\subsubsection{Joint Performance}

The behaviour of the joint of Unit 1 which was reinforced by plain round bars can be contrasted with the behaviour of the joint of Unit $\mathrm{O} 1$ tested by Hakuto et al (11) which was otherwise identical, but reinforced by deformed longitudinal bars. The observed diagonal cracking and shear distortion of the joint core of Unit 1 (see Fig. 3) was significantly less than for Unit O1. The nominal horizontal joint shear stresses at the theoretical flexural strengths of the columns were $0.50 \sqrt{f_{c}^{\prime}}$ for Unit 1 and $0.61 \sqrt{f_{c}^{\prime}}$ for Unit O1.
However, the better joint performance of Unit 1 compared with Unit $\mathrm{O} 1$ was mainly due to the much enhanced concrete strut mechanism in the joint core resulting from the slip of the plain round longitudinal bars.

\subsection{Unit 2}

\subsubsection{Cracking and Damage}

The appearance of Unit 2 at the end of testing is shown in Fig. 7. In the case of Unit 1 the damage concentrated mainly in the columns, where the plastic hinges occurred, and the column displacement component contributed as much as $90 \%$ of the total storey drift at the final loading stage. In the case of Unit 2 the damage spread throughout the whole test unit in the vicinity of the joint, and the column displacement component was $57 \%$ of the total storey drift at the final loading stage. The joint core and beam displacement components contributed about equally to the rest of the total storey deflection at the final testing stage of Unit 2. For Unit 2 the column and beam flexural strengths were almost identical (see Table 3). The damage to the columns of Unit 2 concentrated in the areas adjacent to the joint core as a result of concrete spalling which was associated with much more severe buckling of the longitudinal column bars due to the existence of the compressive axial column load. The damage to the beams concentrated in the wide flexural cracks in the beams adjacent to the joint core. At the theoretical flexural strength of the beams the nominal shear stress in the columns was $0.15 \sqrt{f_{c}^{\prime}}$ and in the beams was also $0.15 \sqrt{f_{c}^{\prime}}$. The actually attained nominal shear stresses were lower than these and evidently were not high enough to cause diagonal tension cracking. The damage in the joint core was by way of extensive diagonal tension cracking. It is evident that presence of the compressive axial load on the columns enhanced the transmission of longitudinal beam bar forces to the joint region through bond for Unit 2, rather than mainly by beam flexural concrete compression as was the case for Unit 1, thus leading to more diagonal cracks in the joint core, and a bigger contribution from the joint core deformation to the total storey drift, compared with the test of Unit 1.

Column bar buckling, which was enhanced by the compressive axial load in the columns, was much more significant for Unit 2 than for Unit 1. Also, for Unit 2 it accelerated the damage to the columns and the joint core as a result of the extensive concrete spalling due to the column bar buckling in the regions adjacent to the joint core and within the joint core. Buckling of the column bars led to the final failure of the unit. As was the case in the test of Unit 1, no diagonal tension cracks were observed in the beams and columns of Unit 2 throughout the test, indicating that the small quantity of transverse reinforcement in the members was more needed for preventing bar buckling than for providing shear strength.

\subsubsection{Load Versus Displacement Response}

Figure 8 shows the storey (horizontal) shear force versus storey (horizontal) displacement and drift hysteresis loops for Unit 2. The measured vertical load versus vertical displacement hysteresis loops for each individual beam are 
shown in Figs. 9 and 10 respectively. The measured hysteresis loops for Unit 2 in Figs. 8, 9 and 10 confirm that the existence of the compressive axial column load did not improve the storey shear versus displacement behaviour of the unit.

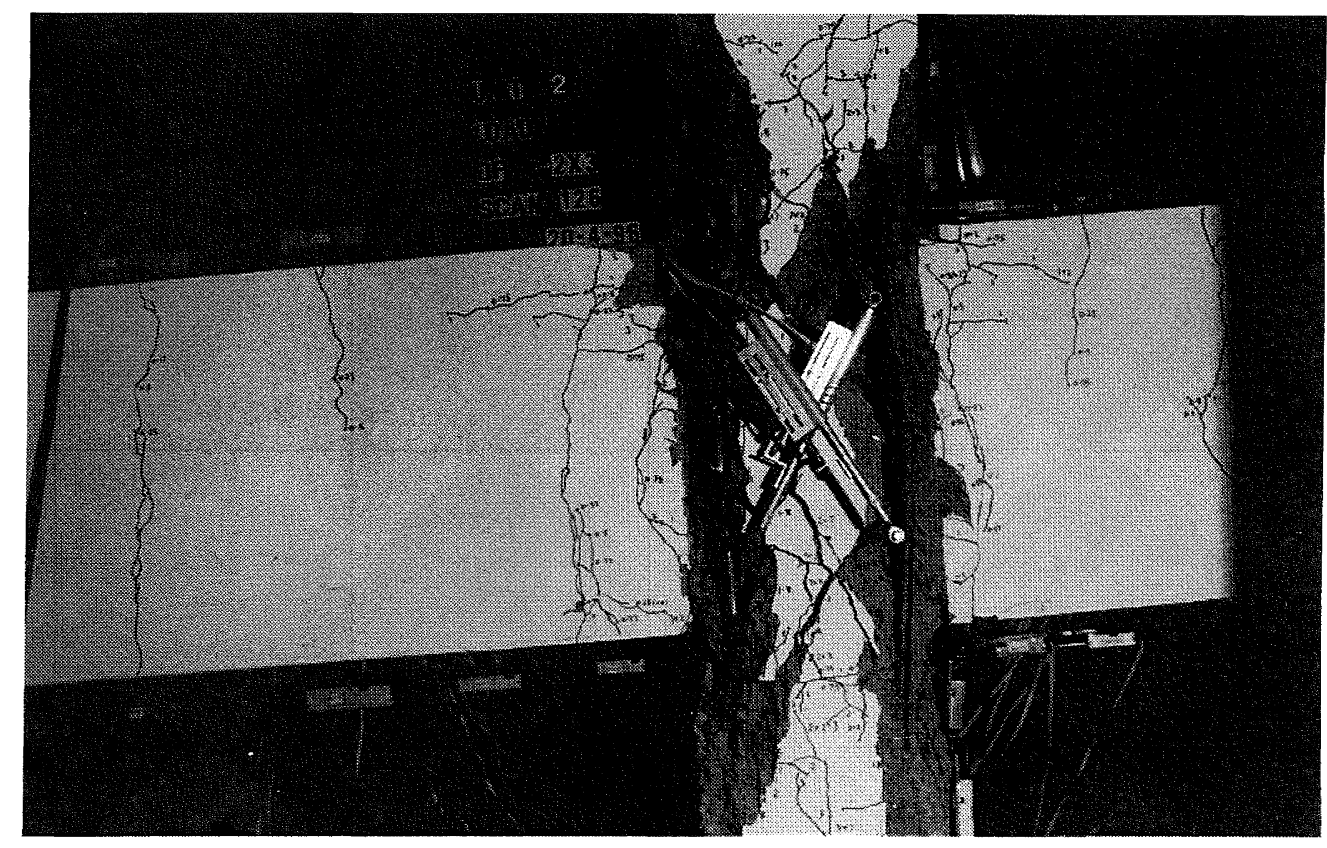

Figure 7: Final appearance of Unit 2

The measured first yield displacement for Unit 2 was equivalent to a storey drift of $2 \%$, and this was comparable with that for Unit 1 . Hence the existence of the compressive axial column load in Unit 2 did not improve the structural stiffness when compared with Unit 1 . This was because, although for Unit 2 the compressive axial column load did suppress severe longitudinal beam bar slip through the joint, and therefore reduced the contributions of beam and column deformations to the total storey deflection, it did increase the joint diagonal tension cracking as a result of the bond of longitudinal beam bars passing through the joint. Hence for Unit 2 the joint core deformation made a greater contribution to the total storey drift.

Significant pinching is observed in Figs. 8, 9 and 10, due to bar slip along the longitudinal reinforcement, premature column bar buckling and the joint shear deformations.

As shown in Fig.8, the maximum strength reached by Unit 2 was in the first loading cycle at a storey drift of $2 \%$ and was $23 \%$ less than the theoretical strength of the unit of $128 \mathrm{kN}$ in terms of storey shear. This can be compared with the test of Unit 1 where the achieved strength at $2 \%$ drift was about $15 \%$ less than the theoretical prediction. Also, for Unit 2 a greater degradation of strength had occurred at $4 \%$ storey drift than for Unit 1 . The lower percentage of the available strength reached by Unit 2 was because column bar buckling was more severe in Unit 2 due to the compressive axial column load present and to the small quantity of column transverse reinforcement.
Also, the strength degradation after the maximum strength was attained, demonstrated by Unit 2 in Fig. 8, was more significant, compared with that by Unit 1 in Fig. 4. This was again because the column bar buckling was accelerated by the existence of the compressive axial column load.

Considerable softening with cyclic loading and pinching of hysteresis loops also occurred, as with Unit 2.

\subsubsection{Measured Strains and Curvatures}

The measured strains and curvatures for Unit 2 also give evidence of severe bond degradation and slip, and more convincing evidence of severe column bar buckling. Again the strains on transverse reinforcement measured by electrical resistance strain gauges did not reach the yield strain, indicating that the requirement of transverse reinforcement for providing shear strength was not critical in this case. This also agreed well with the test observations.

\subsubsection{Joint Performance}

The compressive axial column load on Unit 2 enhanced the transmission of steel force to the surrounding concrete by bond, resulting in more severe diagonal tension cracking and damage in the joint core than for Unit 1. The nominal horizontal joint shear stress at the theoretical flexural strength of the beams was $0.79 \sqrt{f_{c}^{\prime}}$. It is clear that joint shear capacity is still of concern when plain round longitudinal reinforcing bars are used. 


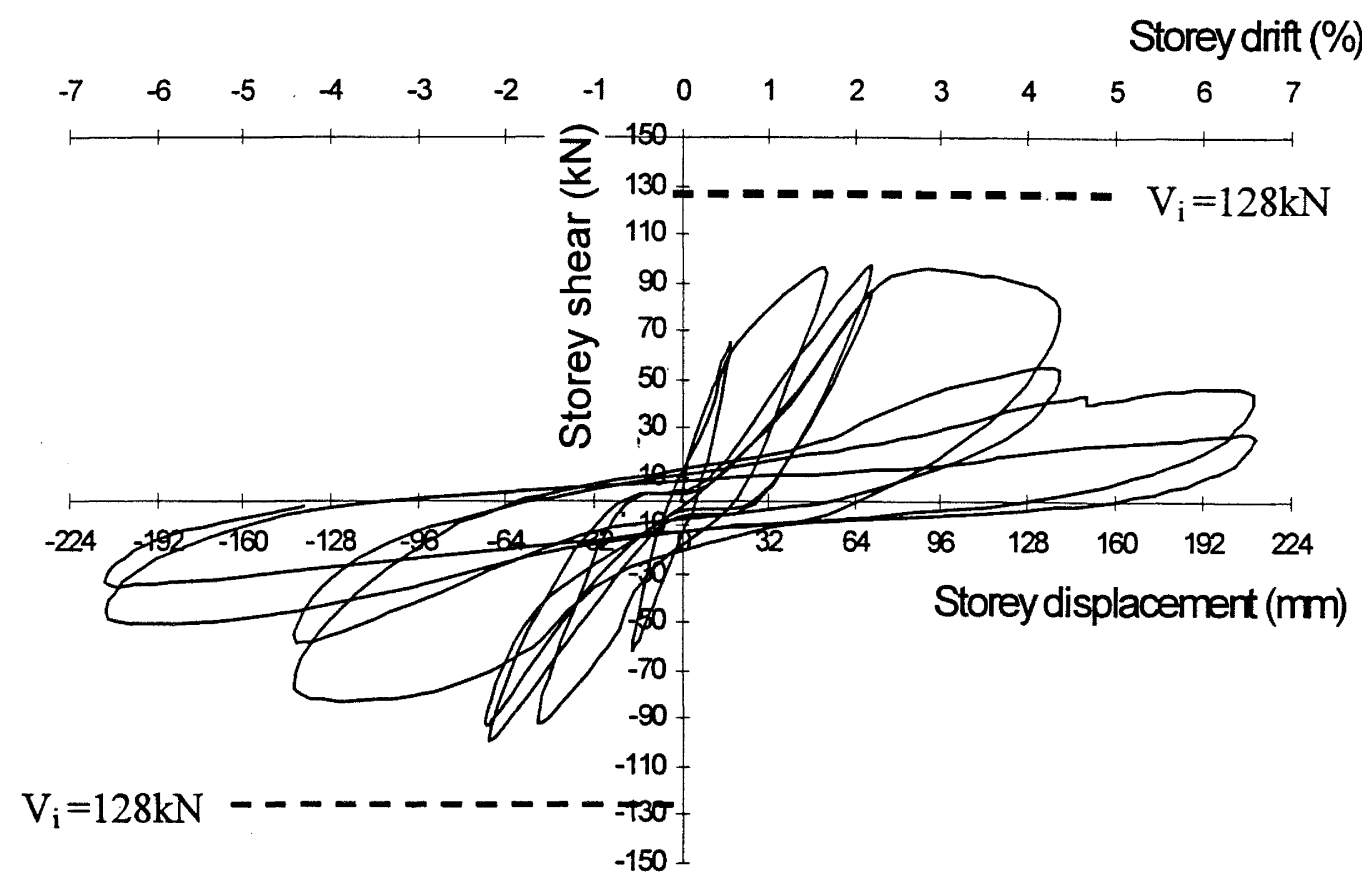

Figure 8: Hysteresis Loops for Storey Shear Versus Storey Displacement of Unit 2

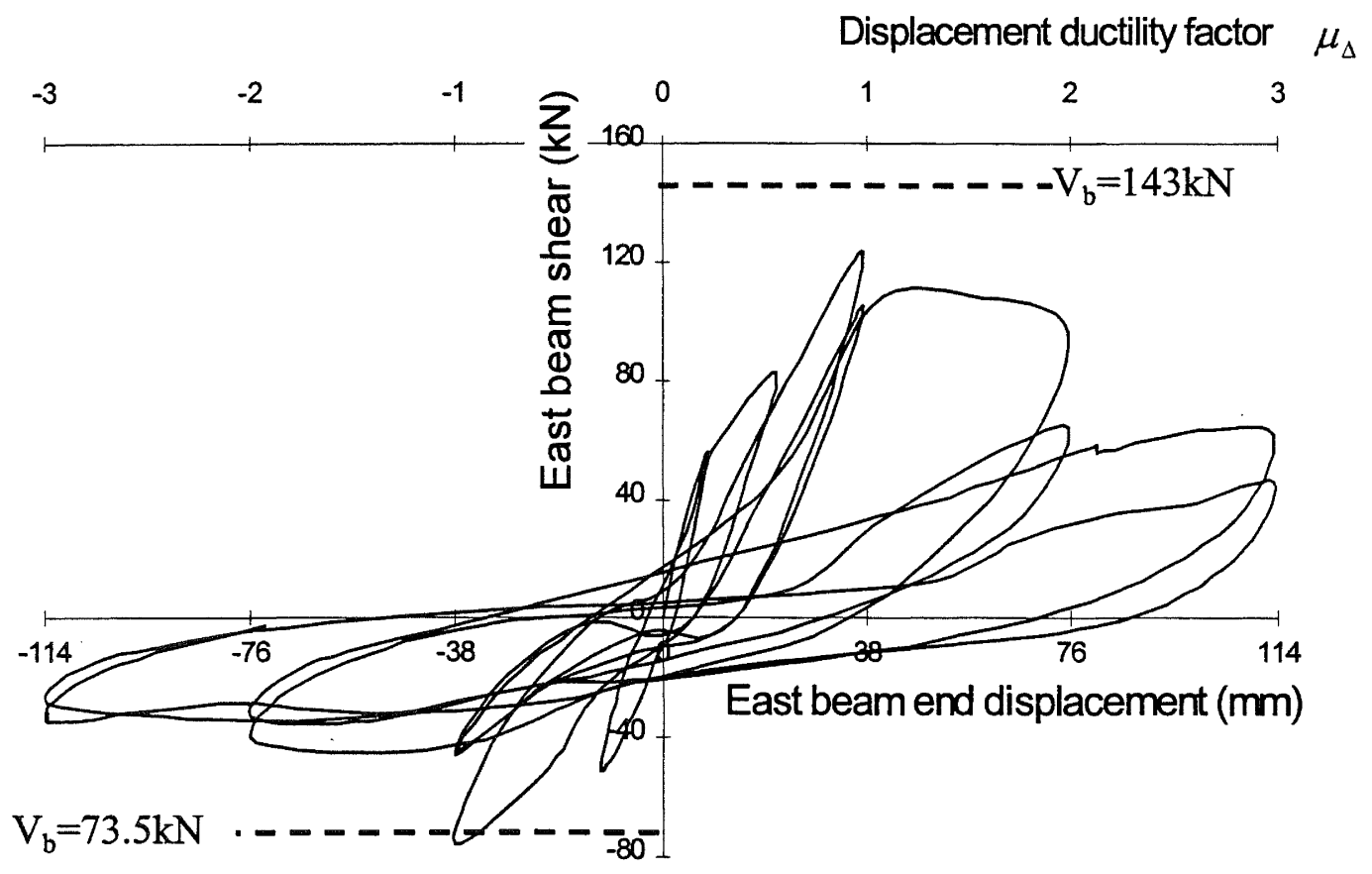

Figure 9: Hysteresis Loops for Beam Shear Versus Beam End Displacement of East Beam of Unit 2 


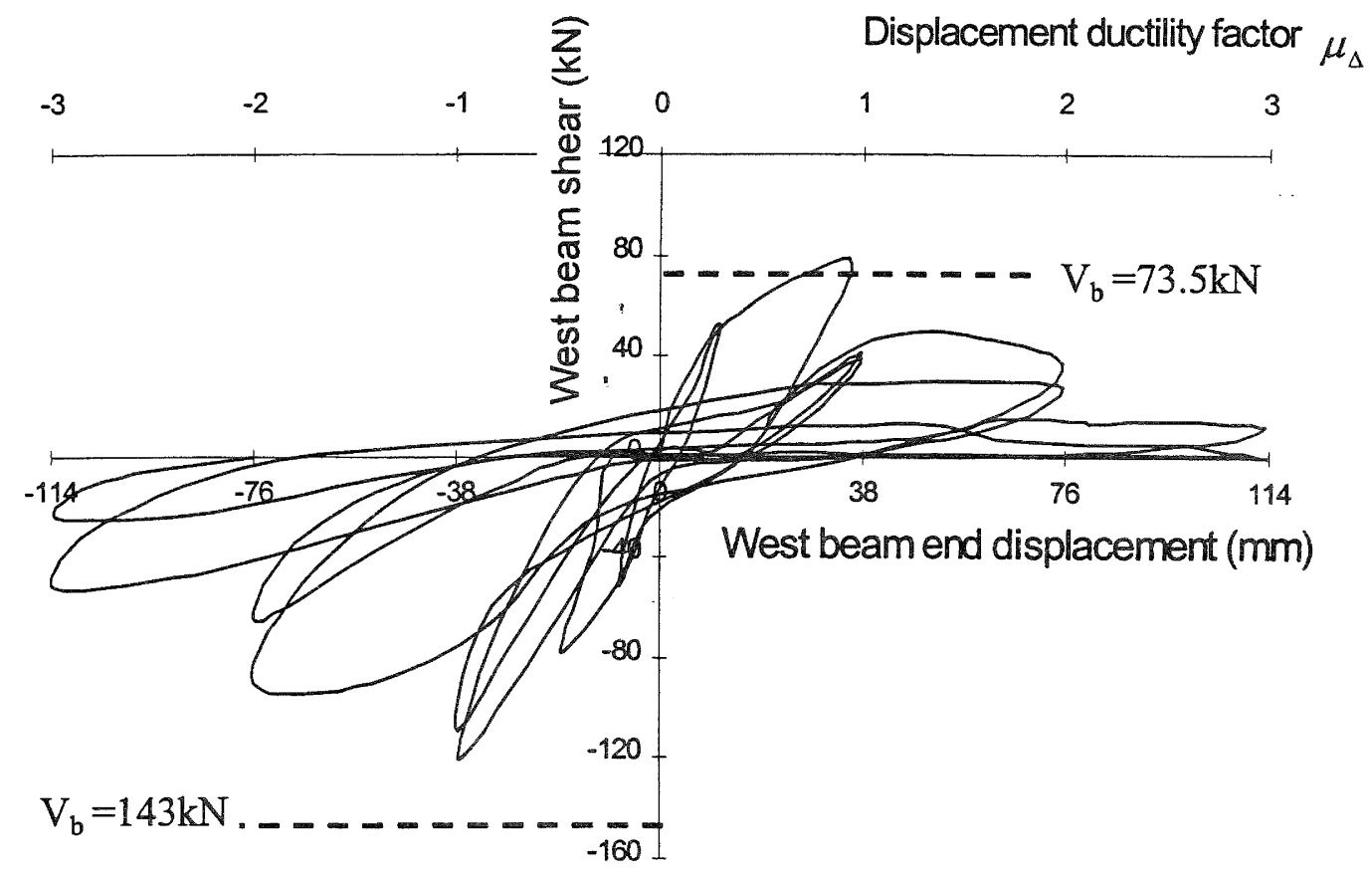

Figure 10: $\quad$ Hysteresis Loops for Beam Shear Versus Beam End Displacement of West Beam of Unit 2

\section{CONCLUSIONS}

1. Simulated seismic load tests were conducted on two identical full-scale one-way interior beam-column joint units (Units 1 and 2) which were reinforced by plain round longitudinal reinforcement and small quantities of transverse reinforcement. The Units were representative of critical regions of reinforced concrete frame structures constructed in New Zealand in the 1950s. The tests showed that similar existing reinforced concrete structures with plain round longitudinal reinforcement designed to outdated seismic codes would show low available stiffness and strength in a major earthquake.

2. Units 1 and 2 were tested with axial compressive column loads of zero and $0.12 f_{c}^{\prime} \mathrm{Ag}$, respectively. The storey shear strengths reached by Units 1 and 2 at a storey drift of $2 \%$ were $85 \%$ and $77 \%$, respectively, of the theoretical strengths based on the flexural strength of the members. Also, the measured stiffnesses of the Units was very low, being about $30 \%$ of the conventionally calculated theoretical stiffness at first yield. This calculated theoretical stiffness at first yield did not include the effect of bond slip in the beam-column joint and in the members. Column bar buckling was found to be the cause of the eventual failure of both Units.

3. The compressive axial column load caused the attained strength of Unit 2 expressed as the percentage of the theoretical strength to be reduced, and also caused the available displacement capacity and the available structural stiffness to be reduced as well. This is because the compressive axial column load enhanced the column bar buckling when the column transverse reinforcement is inadequate.
4. Comparison of the test results of Unit 1, in which the axial column load was zero, with the results of test on an identical beam-column joint unit reinforced by deformed longitudinal reinforcement indicates that the utilisation of plain round longitudinal reinforcement results in lower structural stiffness and a lower strength attainment as a percentage of the theoretical strength. The utilisation of plain round longitudinal reinforcement enhances the joint shear capacity associated with the joint concrete diagonal strut, owing to severe bar slip. Therefore, the use of information on structural behaviour obtained from tests where deformed bars were used for longitudinal reinforcement would be misleading when estimating the probable seismic performance of existing reinforced concrete structures which are reinforced by plain round longitudinal reinforcement and have small amount of transverse reinforcement in members.

5. The flexible performance of the Units in the elastic range (approximately $2 \%$ storey drift at first yield) suggests that the interaction of such frames with masonry infills should not be ignored. Many framed buildings designed before the 1970s, prior to modern seismic design standards, have masonry infills which are not separated from the frames.

\section{ACKNOWLEDGMENTS}

The financial support of the Earthquake Commission (Project $95 / 222$ ) is gratefully acknowledged. Thanks are due to technicians N. Hickey and G. Hill for assistance with the construction and testing of the beam-column units. 


\section{NOTATION}

$\mathrm{A}_{\mathrm{g}}=$ gross area of column section

$\mathrm{b}^{\mathrm{A}}=$ width of beam

$\mathrm{d}=$ distance from extreme compression fibre of beam to centroid of beam tension reinforcement

$\mathrm{d}_{\mathrm{b}}=$ diameter of longitudinal bar

$f_{c}^{\prime}=$ concrete compressive cylinder strength

$\mathrm{f}_{\mathrm{y}}=$ yield strength of longitudinal steel

$\mathrm{f}_{\mathrm{yt}}=$ yield strength of transverse reinforcement

$h_{\mathrm{c}}=$ column depth

$\mathrm{k}=$ numerical coefficient associate with the shear carried by the concrete mechanisms (see Reference 12)

$\mathrm{N}^{*}=$ compressive axial load on column

$\mathrm{p}=$ ratio of area of the top beam longitudinal bars to bd of beam

$\mathrm{p}^{\prime}=$ ratio of area of the bottom beam longitudinal bars to bd of beam

$\mathrm{p}_{\mathrm{t}}=$ ratio of area of the total column longitudinal bars to column gross area

$\mathrm{s}=$ spacing of transverse reinforcement

$\mathrm{V}_{\mathrm{b}}=$ theoretical strength of beam in terms of beam shear force, based on the flexural strength of the beam

$\mathrm{V}_{\mathrm{i}}=$ theoretical strength of the Unit in terms of storey shear force, based on the flexural strength of the members

$\varepsilon_{\mathrm{y}}=$ steel yield strain

$\phi=$ strength reduction factor

$\phi_{\mathrm{u}}=$ ultimate curvature

$\phi_{\mathrm{y}}=$ yield curvature

$\mu_{\Delta}=$ nominal displacement ductility factor, defined as the imposed displacement divided by the first yield displacement.

\section{REFERENCES}

1. Park, R. and Paulay, T. (1975), Reinforced Concrete Structures, John Wiley and Sons, New York.

2. Standards New Zealand (1995), The Design of Concrete Structures, NZS 3101:1995, Standards N.Z., Wellington.

3. Aoyama, H. (1981), A Method for the Evaluation of the Seismic Capacity of Existing Reinforced Concrete Buildings in Japan, Bulletin of the New Zealand National Society for Earthquake Engineering, Vol.14, No. 3, September, pp 105-130.

4. Brunsdon, D. R. and Priestley, M.J.N. (1984), Assessment of Seismic Performance Characteristics of Reinforced Concrete Buildings Constructed Between 1936 and 1975, Bulletin of the New Zealand National Society for Earthquake Engineering, Vol. 17, No. 3, September, pp 163-181.
5. ATC (1989), A Handbook for Seismic Evaluation of Existing Buildings ATC-22, Applied Technology Council, Redwood City, California, 169 p.

6. Rodriguez, M. and Park, R. (1991), Repair and Strengthening of Reinforced Concrete Buildings for Earthquake Resistance, Earthquake Spectra, Vol. 7, No. 3 , pp 439-459.

7. Priestley, M.J.N. and Calvi, G.M. (1991), Towards a Capacity Design Assessment Procedure for Reinforced Concrete Frames, Earthquake Spectra, Vol.7, No.3, pp 413-437.

8. Park, R. (1992), Seismic Assessment and Retrofit of Concrete Structures - United States and New Zealand Developments, Proceedings of Technical Conference of New Zealand Concrete Society, Wairakei, pp 18-25.

9. Rodriguez, M. and Park, R. (1994), Seismic Load Tests of Reinforced Concrete Columns Strengthened by Jacketing, Structural Journal of the American Concrete Institute, Vol. 91, No.2, pp 150-159.

10. Priestley, M.J.N. (1995), Displacement Based Seismic Assessment of Existing Reinforced Concrete Buildings, Proceedings of Pacific Conference on Earthquake Engineering, Vol.2, Melbourne, pp 225-244.

11. Hakuto, S., Park, R. and Tanaka, H. (1995), Retrofitting of Reinforced Concrete Moment Resisting Frames, Research Report 95-4, Department of Civil Engineering, University of Canterbury, August.

12. Park, R. (1997), A Static Force-Based Procedure for the Seismic Assessment of Existing Reinforced Concrete Moment Resisting Frames, Bulletin of the New Zealand National Society for Earthquake Engineering, Vol. 30, No. 3, pp 213-226.

13. Park, R., Billings, I. J., Clifton, G. C., Cousins, J., Filiatrault, A., Jennings, D.N., Jones, L.C.P., Perin, N.D., Rooney, S.L., Sinclair, J., Spurr, D.D., Tanaka, H. and Walker, G. (1995), The Hyogo-ken Nanbu Earthquake(The Great Hanshin Earthquake) of 17 January 1995. Report of the NZNSEE Reconnaissance Team, Bulletin of the New Zealand National Society for Earthquake Engineering, Vol. 28, No.1, pp 1- 98. 